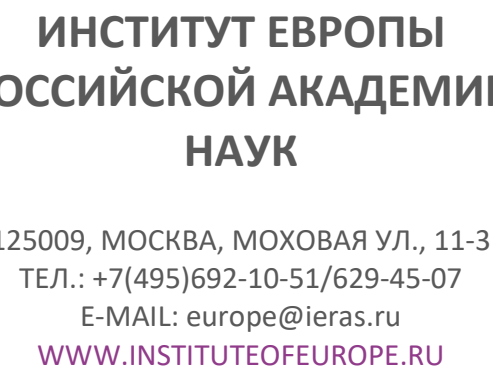

ИНСТИТУТ ЕВРОПЫ HAYK

INSTITUTE OF EUROPE RUSSIAN ACADEMY OF SCIENCES

125009, MOSCOW, MOKHOVAYA STR., 11-3

TEL.: +7(495)692-10-51/629-45-07

E-MAIL: europe-ins@mail.ru WWW.INSTITUTEOFEUROPE.RU

Статья в журнале «Аналитические записки Института Европы РАН» №17, 2021 (№247)

\title{
Выборы в Ландтаг Саксонии-Ангальт - последняя репетиция перед выборами в Бундестаг
}

\section{Владислав Борисович Белов}

кандидат экономических наук, ведущий научный сотрудник, заместитель директора по научной работе, заведующий Отделом страновых исследований, руководитель Центра германских исследований Института Европы РАН

\begin{abstract}
Аннотация. 6 июня 2021 года в небольшой восточногерманской земле Саксония-Ангальт прошли выборы в ландтаг. Состоявшиеся ровно за 16 недель до выборов в Бундестаг, они стали промежуточной пробой сил этаблированных партий, в определённой степени отразив соотномение сил - по крайне мере, на Востоке Германии - между основными претендентами на формирование будущего федерального правительства. Автор анализирует итоги выборов в земельный парламент и делает прогноз дальнеймего развития событий.
\end{abstract}

Ключевые слова: Германия, Саксония-Ангальт, выборы, ландтаг, Бундестаг.

Автор. Белов Владислав Борисович - кандидат экономических наук, ведущий научный сотрудник, заместитель директора по научной работе, руководитель Отдела страновых исследований, руководитель Центра германских исследований ИЕ РАН. Адрес: 125009, Россия, Москва, ул. Моховая, д. 11, стр. 3. Email: vladisbelov@yandex.ru.

DOI: http://doi.org/10.15211/analytics172021 
Прошедшие 6 июня 2021 года выборы в земельный парламент Саксонии-Ангальт стали последними перед 26 сентября, когда будет избираться новый состав Бундестага. Поэтому к ним было обращено особое внимание экспертного сообщества.

\section{Сенсация не состоялась}

Основная интрига состояла в том, какое количество голосов получат партии правящей коалиции, в первую очередь, ХДС и «Союз 90/Зелёные», а также нерукопожатная «Альтернатива для Германии» и свободные демократы. Средневзвешенные показатели опросов, опубликованных в начале июня, свидетельствовали о лидерстве христианских демократов ${ }^{1}-28,5 \%$ (минус $1,3 \%$ по сравнению с 2016 г.), за которыми следовала АдГ $24,0 \%$ (-0,3\%), партия «Левая» - 11,1\% (-5,2\%), СДПГ - 10,3\% (-0,3\%), зелёные - 8,8\% $(+3,6 \%)$, СвДП $-7,4 \%(+2,5 \%)^{2}$.

Предварительные итоги по состоянию на утро 7 июня оказались весьма далеки от прогнозных. Христианские демократы получили неожиданно высокие 37,1\% (+7,4\%), АдГ, наоборот, низкие 20,8\% (-3,4\%), а другие указанные выше партийные образования, соответственно - $11,0 \%(-5,3 \%), 8,4 \%(-2,2 \%), 5,9 \%(+0,8 \%)$ и $6,4 \%(+1,6 \%)$.

Таким образом, не состоялась сенсация, ожидавшаяся отдельными экспертами - АдГ не опередила ХДС и не набрала больше голосов по сравнению с прошлыми выборами, оставшись при этом ведущей оппозиционной силой в ландтаге. Не смогли преодолеть заветный 10\%-ный барьер зелёные. Более того, их результат оказался скромным - почти на уровне 2016 г. Существенно улучшили своё положение свободные демократы, преодолевшие 5\%-ный барьер (им не удавалось это с 2011 г.) и уже в ходе предвыборной кампании заявившие о готовности войти в новую правительственную коалицию. В явном проигрыше оказались левые, которые за прошедший год окончательно потеряли статус основной политической протестной силы (в марте 2020 г. за них были готовы проголосовать 18\% граждан земли), и социал-демократы, скатившиеся ниже $10 \%$.

Из 1,8 млн граждан, имеющих право голоса (всего в Саксонии-Ангальт проживает 2,2 млн человек), в голосовании приняли участие около 60,3\% (в 2011 г. - 51,2\%, в 2016 г. 61,1\%). Примерно 30\% проголосовали по почте (12,0\% и 13,7\% в 2011 и 2016 гг.) $)^{3}$. За 10 дней до голосования 58\% опрошенных избирателей сообщили, что уже решили за кого отдадут свои голоса; 16\% сказали, что не исключают изменения своих электоральных предпочтений к моменту голосования. В выборах приняли участие 449 кандидатов от 22 партий.

\footnotetext{
1 Данные опросов существенно различались. Например, компания INSA накануне выборов опубликовала результаты, согласно которым «Альтернатива для Германии» на 1\% опережала ХДС.

${ }^{2}$ Landtagswahl in Sachsen-Anhalt 2021. 06.06.2021. URL: https://www.bundestagswahl-2021.de/landtagswahlsachsen-anhalt/ (дата обращения: 06.06.2021)

${ }^{3}$ Ibid.
} 
Христианские демократы своей победой во многом обязаны лидеру их земельной организации Райнеру Хазелоффу (Reiner Haseloff) ${ }^{4}$, который с 2011 по 2021 г. был премьер-министром Саксонии-Ангальт и весной заявил о решимости в третий раз занять этот пост ${ }^{5}$. Политик весьма популярен в земле, в т.ч. благодаря своей непримиримой позиции по отношению к правым радикалам и популистам. Две трети граждан, включая часть сторонников АдГ, считают его хорошим и компетентным премьер-министром.

Основным политическим противником был 55-летний Оливер Кирхнер (Oliver Kirchner), возглавляющий с 2018 г. фракцию АдГ в ландтаге, в который он был избран в 2016 году. Он входил в т.н. «Крыло» (Flügel) АдГ, объединявшее правоэкстремистских членов партии во главе с одиозным нацистом Б. Хёке. В апреле 2020 г. оно было распущено. Считается, что в ландтаге Саксонии-Ангальте сформировалась самая праворадикальная фракция АдГ в Германии. Именно Земельная организация АдГ находится под наблюдением Ведомства по охране Конституции.

Что касается шпитценкандидатов ${ }^{6}$, то электорату в основном был известен Хазелофф. Других ведущих партийных функционеров большинство избирателей, даже из рядов сторонников, почти не знали ${ }^{7}$.

\section{Итоги «кенийской» коалиции}

Созданная в 2016 г. т.н. «кенийская» коалиция в составе ХДС, СДПГ и «Союз 90/Зелёные» ${ }^{8}$ была новой и необычной для политического ландшафта Германии. Такая комбинация была вынужденной и, по сути, единственно возможной из-за «Альтернативы для Германии», получившей четверть всех мест в ландтаге. Других политически приемлемых коалиционных вариантов не было, и противодействие АдГ стало основной связующей нитью между коалиционерами. В 2016-2021 гг. партнёры

\footnotetext{
${ }^{4}$ Р. Хазелофф - ровесник А. Меркель (67 лет). Как и канцлерин, он защитил кандидатскую диссертацию по физике.

${ }^{5}$ В 2011-2016 гг. в ландтаг Саксонии-Ангальт входили 4 партии: ХДС (41 мандата), «Левая» (29), СДПГ (26) и «Союз 90/Зелёные» (9). В 2016-2021 гг. количество мест у этих партий изменилось: 30, 16, 11 и 5. К ним добавилась пятая партия - АдГ, получившая 21 мандат. В связи с уменьшением числа избирательных округов с 43 до 41 количество депутатов в ландтаге нового созыва сократится с 87 до 83. См.: Landtagswahl in Sachsen-Anhalt... Op. cit.

${ }^{6}$ Шпитценкандидат СДПГ - родившаяся в 1977 г. Катя Пэле (Katja Pähle), избранная в земельный парламент в 2011 г. и возглавляющая фракцию социал-демократов с 2016 г. «Союз 90/Зелёные» представляла Корнелия Люддеманн (Cornelia Lüddemann), избранная в ландтаг с 2011 г. и председатель фракции с 2016 года. Свободные демократы своим лидером определили Лидию Хюскенс (Lydia Hüskens), заместителя председателя земельной организации СвДП в Саксонии-Ангальт с 2011 года. Лидер левых 45-летняя Ева фон Ангерн (Eva von Angern), депутат ландтага с 2002 г. и сопредседатель фракции с 2020 $\Gamma$.

7 Ehni, E, Schwarz-Rot-Grün hätte Mehrheit. 27.05.2021. URL: https://www.tagesschau.de/inland/deutschlandtrend/vorwahlumfrage-sachsen-anhalt-101.html (дата обращения: 31.05.2021)

8 Коалиция названа по партийным цветам партнёров, которые соответствуют цветовой гамме государственного флага Кении - черно-красно-зелёной.
} 
неоднократно конфликтовали по самым разным вопросам. Тем не менее, Р. Хазелофф остался доволен сотрудничеством с обеими партиями, с которыми ХДС приняло много важных законопроектов. Среди социал-демократов он высоко ценил работу министра здравоохранения Петры Гримм-Бенне (Petra Grimm-Benne) особенно как «кризисного пандемийного менеджера» и министра экономики Армина Виллингманна (Armin Willingmann $)^{9}$.

В декабре 2020 г. в земельном правительстве возникли существенные разногласия касательно повышения обязательного сбора за пользование радио. Министр внутренних дел Хольгер Шталькнехт (Holger Stahlknecht) поставил вопрос о разрыве коалиционных отношений с СДПГ и зелёными и создании правительства меньшинства, состоящего только из представителей ХДС. Однако оно могло стать дееспособным только при поддержке депутатов АдГ. В этой ситуации премьер-министр принял решение уволить Шталькнехта, который считался одним из его самых любимых политиков. Именно после этого Хазелофф отказался уходить на пенсию и заявил о готовности возглавить правительство по итогам выборов, в т.ч. для того, чтобы жёстко противостоять любым попыткам сближения с АдГ.

\section{Усиление позиций А. Лашета}

У Р. Хазелоффа сложились непростые отношения с А. Лашетом, изначально он поддерживал его конкурентов - Ф. Мерца в борьбе за пост председателя ХДС, а затем М. Зёдера как наиболее подходящего, с его точки зрения, кандидата в канцлеры. При этом содержательные вопросы для Хазелоффа не играли особой роли - основными были высокие рейтинги данных политиков. Ставка на личную популярность стала ключевой и для его предвыборной кампании. Лидер земельных христианских демократов поставил во главу угла известные лозунги К. Аденауэра «Никаких экспериментов» и В. Кречманна «Вы знаете меня» и сделал акцент на стремлении большинства избирателей к двум основным консервативным ценностям - сохранению стабильности и уверенности в компетенциях лидера. В этом контексте он выстроил непримиримую борьбу против АдГ.

А. Лашет не затаил обиды на своего коллегу и принял активное участие в предвыборной борьбе земельного ХДС, успех которой после мартовских поражений в РейнландПфальце и Баден-Вюртемберге был необходим ему лично. Высокий результат партии на выборах оказался особенно важным для кандидата на пост канцлера. Убедительная победа земельных христианских демократов стала косвенным подтверждением правильности принятого руководством партии 19 апреля решения в пользу Лашета и несколько укрепила его позиции на федеральном уровне.

\section{Роль выборов для этаблированных партий}

\footnotetext{
${ }^{9}$ Wahl in Sachsen-Anhalt: Wie bunt wird die neue Regierung? 21.05.2021. URL: https://www.zeit.de/news/202105/21/wahl-in-sachsen-anhalt-wie-bunt-wird-die-neue-regierung (дата обращения: 31.05.2021)
} 
АдГ, за которую проголосовал каждый пятый избиратель, подтвердила свои претензии на статус одной из ведущих политических сил в Саксонии-Ангальте. По мнению политолога Михаила Колькманна (Michael Kolkmann) из восточногерманского Университета г. Галле-Виттенберг, АдГ за прошедшие годы существенно усилила сетевые связи на коммунальном уровне, укрепила личный состав и структуру партии и имеет хорошие шансы продолжить партийную работу в этом направлении, используя финансовые средства фракции и политического фонда партии ${ }^{10}$.

В предвыборной кампании АдГ уделила особое внимание пандемии и критике ограничительных мер федерации и земли. Но центральное место по-прежнему занимала тема ужесточения политики по отношению к мигрантам и беженцам. Так, например, земельная организация АдГ считает, что последние не должны получать электронные медицинские карты, которые недавно заменили традиционные полисы медицинского страхования. Партия пользуется особенно высокой популярностью в южных частях региона, где высока безработица (во времена ГДР здесь была размещена высокоразвитая химическая промышленность, многие предприятия которой в ходе объединения были закрыты).

Примечательно, что у АдГ в ходе последних выборов по сравнению с другими партиями была самая высокая доля молодых избирателей, т.е. тех, кто не знаком с особенностями социалистического периода. В этом контексте в центре внимания оказалось высказывание депутата Бундестага от ХДС, уполномоченного федерального правительства по делам восточных земель Марко Вандервица (Marco Wanderwitz), которое он сделал в конце мая в подкасте газеты Frankfurter Allgemeine Zeitung в отношении восточногерманских граждан: «Мы имеем дело с людьми, чьи взгляды частично были сформированы диктатурой таким образом, что они не приняли демократию даже 30 лет спустя» ${ }^{11}$.

Абсолютное большинство восточных немцев негативно восприняло такую оценку своего соотечественника (Вандервиц родился и вырос в г. Карл-Маркс-Штадт, ныне г. Хемниц). Она в целом расходится с результатами официального исследования, посвящённого итогам тридцатилетия объединения Германии и презентованного общественности осенью 2020 г. ${ }^{12}$ Уполномоченный контекстно затронул существующее недовольство части восточных немцев особенностями воссоединительных процессов, на котором АдГ во многом выстроила свою популярность. К негативным моментам они относят, например, минимальное количество граждан Восточной Германии,

\footnotetext{
${ }^{10}$ Busch, F. AfD-Hochburg und Koalitionslabor: Sachsen-Anhalt wählt einen neuen Landtag. 25.05.2021. URL: https://web.de/magazine/politik/wahlen/landtagswahlen/sachsen-anhalt/afd-hochburg-koalitionslabor-sachsenanhalt-waehlt-landtag-35832466 (дата обращения: 31.05.2021)

${ }^{11}$ Stepatt, T. Ostbeauftragter über AfD-Wähler: „Nach 30 Jahren nicht in der Demokratie angekommen“. 28.05.2021. URL: https://www.faz.net/podcasts/f-a-z-podcast-fuer-deutschland/ostbeauftragter-ueber-afdwaehler-nach-30-jahren-nicht-in-der-demokratie-angekommen-17363632.html (дата обращения: 31.05.2021)

${ }_{12}$ Огнева, А. 30 лет объединения Германии: состояние и перспективы. - в кн.: Германия. 2020 / [В.Б. Белов и др.; отв. ред. В.Б. Белов]. - М. : Ин-т Европы РАН, 2021. - С. 16-34. DOI: http://dx.doi.org/10.15211/report12021_379
} 
представленных в руководящих органах и структурах федеральной власти и крупного бизнеса ${ }^{13}$. Шпитценкандидат от партии «Левая» использовала этот факт в своей кампании, выбрав слоган для предвыборного плаката: «Отберите у весси (западногерманских граждан - прим. авт.) командование».

Однако вопреки ожиданиям экспертов нелицеприятная оценка Вандервица не содействовала притоку голосов к АдГ и левым. Наоборот, этим воспользовался Р. Хазелофф. Критикуя такое заявление, в своём обращении к избирателям он сказал, что за прошедшие десятилетия они стали одними из самых демократических граждан Германии, даже демократичнее западногерманских. Косвенно это был призыв осмыслить опасность правого популизма и радикализма и не допустить превращения Саксонии-Ангальт в их главный оплот.

И этот призыв сработал. Он стал одним из мотивов, побудивших сторонников других партий отдать свои голоса христианским демократам. По предварительным данным, это сделали 15 тыс. приверженцев социал-демократов, 13 тыс. левых и 11 тыс. сторонников АдГ. К ним присоединились 35 тыс. т.н. «неизбирателей» (Nichtwähler).

Прошедшие выборы имеют важное значение для других федеральных этаблированных партий и их лидеров, в т.ч. для со-председателя «Союза 90/Зелёных» и кандидата в канцлеры Аннелизы Бербок. Традиционно зелёные не пользуются популярностью в новых федеральных землях. Несостоявшийся прорыв и лишь незначительное увеличение количества полученных голосов по сравнению с 2016 г. говорят о том, что в последующие недели «Союзу 90/Зелёным» предстоит серьёзная предвыборная работа в Восточной Германии, без голосов которой им не достичь желаемых результатов на федеральных выборах в сентябре 2021 года. Итоги стали холодным душем для руководства партии и лично Бербок. Есть шанс, что партия не войдёт в новую земельную коалицию.

В явном проигрыше оказались партия «Левая» и СДПГ. Выборы ещё раз наглядно показали, что их обновленному руководству пока не удаётся сформулировать привлекательные и отвечающие на актуальные вызовы положения, способные остановить отток сторонников и привлечь новых, особенно из рядов молодёжи. На Востоке Германии они во многом утратили свою традиционную роль основных защитников интересов «простых» граждан и наёмных работников. Федеральные лидеры вместо поиска новых парадигм пока ограничиваются критикой своих коалиционных партнёров.

Наряду с ХДС к победителям земельных выборов следует отнести свободных демократов, опередившие зелёных. Они провели содержательную кампанию, поставив во главу угла наряду с борьбой с пандемией необходимость уменьшения роли государства в экономике и повышения эффективности использования рыночных механизмов. Председатель СвДП Кристиан Линднер считает, что партия имеет шансы войти не только в земельную правительственную коалицию, но и по итогам

\footnotetext{
${ }^{13}$ Там же.
} 
сентябрьских выборов - в федеральную. Одновременно он подчеркнул поддержку, оказанную в Саксонии-Ангальте сторонниками свободных демократов ХДС, - многие из них решили, что более важно отдать свои голоса основной политической силе, противостоящей «Альтернативе для Германии».

\section{Выводы}

Р. Хазелоффу и его коллегам удалось консолидировать электорат не только ХДС, но и других политических сил в противостоянии с «Альтернативой для Германии», предвыборную кампанию которой активно поддерживал Б. Хёке. Наряду с успехами в борьбе с коронакризисом, реализацией экономических программ, поддержкой сферы образования это обеспечило убедительную победу христианских демократов, укрепившую положение и их федерального лидера А. Лашета.

В последующие недели, а возможно и месяцы, будет решаться непростой вопрос о формировании под руководством Р. Хазелоффа следующей правительственной коалиции. Неожиданно большое количество мест в теперь уже шестипартийном ландтаге ${ }^{14}$ позволяет христианским демократам рассматривать самые разные варианты - от двухпартийного правительства (с СДПГ) до сохранения прежней «кенийской» коалиции и формирования «германской» (ХДС, СДПГ, СвДП $\left.{ }^{15}\right)$ или «ямайской» $($ ХДС, «Союз 90/Зелёные», СвДП) коалиций.

Нерукопожатными для ХДС по-прежнему являются «Альтернатива для Германии» и партия «Левая». Несмотря на жёсткое позиционирование по отношению к АдГ и консолидацию партийных рядов в последние месяцы, часть христианских демократов земельной организации по-прежнему считают АдГ меньшим злом по сравнению с левыми и не исключает в будущем возможное сближение с «политическими изгоями». Подобное развитие событий может стать серьёзным вызовом для лидера земельных христианских демократов.

Центральные темы предвыборной партийной борьбы в Саксонии-Ангальт оказались релевантными и для федерального уровня: каковы перспективы преодоления пандемии и коронакризиса; что будет с экономикой, бизнесом и рабочими местами ${ }^{16}$; как будут решаться проблемы со средним и высшим образованием. Федеральные лидеры всех этаблированных партий внимательно следили за предвыборной кампанией и выборами, включая их нынешние экспертные оценки. Они обязательно будут учтены в начавшейся борьбе за места в Бундестаге.

Определённые моменты будут приняты во внимание при обсуждении и принятии программы зелёных 11-13 июня, а также при подготовке программы союза ХДС/ХСС.

\footnotetext{
14 По итогам выборов количество избранных в ландтаг депутатов составило 97 человек.

15 Такого коалиционного варианта в истории ФРГ ещё не было. Если он осуществится, то СаксонияАнгальт, как и в 2016 г., вновь станет лабораторией, где впервые проходит такой политический эксперимент.

16 В этом контексте отметим конструктивное отношение Р. Хазелоффа к развитию всесторонней экономической кооперации с Россией.
} 
Эти партии по-прежнему могут рассчитывать на получение более половины мест в будущем Бундестаге. Открытым остаётся вопрос о перспективах их возможного коалиционного сотрудничества как на земельном, так и федеральном уровнях.

Дата выпуска: 7 июня 2021 года

Elections to the Landtag of Saxony-Anhalt - final rehearsal before elections to the Bundestag

Annotation. On June 6, 2021, Landtag elections were held in a small Eastern German state of SaxonyAnhalt. Held 16 weeks prior to elections to the Bundestag, they became an intermediate test of strength of the established parties, reflecting the balance of power - at least in the East of Germany - between the main contenders for formation of the future federal government. The author analyzes results of the elections to the Land Parliament and makes a forecast of further developments.

Key words: Germany, Saxony-Anhalt, elections, Landtag, Bundestag.

Author. Vladislav Belov, Candidate of Sciences (Economics), Deputy Director of IE RAS, Head of the Department for Countries Studies, Head of the Center for German Studies, Institute of Europe, Russian Academy of Sciences. Address: 11-3, Mokhovaya str., Moscow, Russia, 125009. E-mail: vladisbelov@yandex.ru.

DOI: $\underline{\text { http://doi.org/10.15211/analytics172021 }}$

http://www.zapiski-ieran.ru

Release date: June 7, 2021. 